\title{
Pendekatan Metode Ward And Peppard Untuk Perencanaan Strategis Sistem Informasi DISPERINNAKER Kota Salatiga
}

\author{
Shania Arum Destyarini', Andeka Rocky Tanaamah \\ ${ }^{1,2}$ Sistem Informasi, Fakultas Teknologi Informasi, Universitas Kristen Satya Wacana \\ 3Jl. Blotongan, Sidorejo, Kota Salatiga, Jawa Tengah \\ e-mail :682017023@student.uksw.edu1, atanaamah@uksw.edu²
}

\begin{abstract}
Abstrak
DISPERINNAKER Kota Salatiga merupakan instansi pemerintah yang bergerak pada bidang Perindustrian dan Ketenagakerjaan. Sistem informasi dan teknologi informasi (SI/TI) merupakan sarana untuk mencapai kesuksesan dalam menunjang keberhasilan visi dan misi pemerintah guna mewujudkan pemerintahan era digital. Namun, saat ini proses bisnis pada DISPERINNAKER belum semuanya didukung dengan penggunaan SI/TI, sehingga proses kinerjanya belum berjalan dengan efektif dan efisien. Maka dari itu diperlukannya sebuah perencanaan strategis SI/TI yang baik dan terencana. Penelitian ini menggunakan pendekatan metode Ward and Peppard yang terdiri dari Analisis SWOT dengan tambahan Matrik IFE dan EFE yang digunakan untuk mengevaluasi faktor-faktor internal dan eksternal dengan melihat kekuatan, kelemahan, peluang, dan ancaman utama dalam organisasi, Analisa Value Chain, Metode Critical Success Factors (CSFs) Berdasarkan IT Balanced Scorecard, dan Mcfarlan's Strategic Grid yang akan menghasilkan gambaran kebutuhan sistem informasi, solusi, dan rekomendasi strategi sistem informasi yang nantinya dapat dirumuskan sebagai perencanaan strategi untuk rencana implementasi yang akan dilakukan dalam kurun waktu 4 (empat) tahun yang akan datang.
\end{abstract}

Kata kunci-Ward and Peppard, SWOT, Value Chain, Balanced Scorecard, McFarlan's Strategic Grid

\begin{abstract}
Abstrak
DISPERINNAKER of Salatiga City is a government agency engaged in the Industry and Manpower sector. Information systems and information technology (IS / IT) are tools to achieve success in supporting the success of the government's vision and mission in order to create a digital era government. However, currently not all of the business processes at DISPERINNAKER are supported by the use of IS / IT, so that the performance process has not been running effectively and efficiently. Therefore, a good and well-planned IS / IT strategic plan is needed. This study uses the Ward and Peppard method approach which consists of a SWOT analysis with the addition of the IFE and EFE matrices which are used to evaluate internal and external factors by looking at the main strengths, weaknesses, opportunities, and threats in the organization, Value Chain Analysis, Critical Success Method. Factors (CSFs) Based on the IT Balanced Scorecard, and Mc Farlan's Strategic Grid which will produce an overview of information system requirements, solutions, and information system strategy recommendations which can later be formulated as strategic planning for implementation plans that will be carried out within 4 (four) years which will come.
\end{abstract}

Keywords-Ward and Peppard, SWOT, Value Chain, Balanced Scorecard, McFarlan's Strategic Grid 


\section{PENDAHULUAN}

Perkembangan teknologi informasi dan sistem informasi di era globalisasi saat ini yang semakin meningkat membuat sebuah organisasi dituntut untuk mengedepankan fasilitas teknologi informasi yang ada. Penggunaan fasilitas teknologi informasi pada organisasi harus berjalan secara maksimal untuk menunjang kinerja proses bisnis organisasi nantinya. Karena perannya yang strategis, teknologi informasi juga dapat dijadikan sebagai senjata bagi sebuah organisasi dalam instansi pemerintah [1](Thomas, 2014). Oleh karena itu, strategi SI/TI dapat digunakan dalam instansi pemerintah untuk menunjang kualitas SI/TI dan meningkatkan nilai organisasi untuk terciptanya visi misi dan pemerintahan E-Government.

Dinas Perindustrian dan Tenaga Kerja Kota Salatiga (DISPERINNAKER) merupakan instansi pemerintah yang bergerak pada bidang Perindustrian dan Ketenagakerjaan yang terletak di JL. Ki Penjawi No.12 Salatiga. Dinas Perindustrian dan Tenaga Kerja mempunyai tugas pokok yaitu melaksanakan urusan pemerintahan daerah di Bidang Industri dan Tenaga Kerja berdasarkan asas ekonomi dan tugas pembantuan. Dinas Perindustrian dan Tenaga Kerja Kota Salatiga mempunyai 3 bidang yaitu bidang sekretariat, bidang industri, dan bidang tenaga kerja.

Perencanaan program kerja yang strategis merupakan cara untuk menerapkan sumber daya, produk-produk atau jasa yang akan disediakan secara optimal. Saat ini organisasi sektor publik sedang menghadapi berbagai tantangan dan tuntutan untuk bekerja lebih efisien [2](Sudiarsa, 2011). Program pemerintah yang baik (good governance) dan peningkatan pelayanan publik yang efektif dan efisien memerlukan adanya kebijakan dan strategi pengembangan e-government [3](Kemkominfo, 2003).

Kegiatan yang dilakukan pada DISPERINNAKER Kota Salatiga saat ini masih banyak yang belum menggunakan SI/TI untuk menunjang aktivitas yang dilakukan pada sebuah organisasi agar lebih efisien dan efektif. Adanya SI/TI pastinya sangat penting bagi pengelolaan data dan pengarsipan data. Pengelolaan data yang kurang efektif akan mengakibatkan dampak buruk bagi instansi tersebut. Dengan minimnya SI/TI untuk mengelola proses kinerja maka akan mengakibatkan proses kinerja menjadi kurang efektif dan efisien. Permasalahan yang dihadapi oleh DISPERINNAKER Kota Salatiga yaitu belum optimalnya pemanfaatan SI/TI dalam mengembangkan proses kinerja yang ada pada DISPERINNAKER Kota Salatiga seperti pemeliharaan data dan pengarsipan data yang mengakibatkan sering terjadinya kesalahan data (random). Berdasarkan hal tersebut diperlukannya proses perencanaan strategis sistem informasi yang selaras dengan strategi organisasi yang ada pada DISPERINNAKER. Melalui perencanaan strategi ini dapat dilihat kondisi-kondisi internal dan eksternalnya, sehingga dapat mengantisipasi perubahan lingkungan organisasi. Penelitian (Clement \& Salois-Swallow, 1995) ini bertujuan untuk menyusun rumusan perencanaan strategi SI/TI pada DISPERINNAKER Kota Salatiga dengan menggunakan pendekatan metode yang dikembangkan oleh John Ward dan Joe Peppard (Ward and Peppard) [4]. Adapun tools yang digunakan pada metode Ward and Peppard terdiri dari Analisis SWOT dengan tambahan Matrik IFE dan EFE yang digunakan untuk mengevaluasi faktor-faktor internal dan eksternal dengan melihat kekuatan, kelemahan, peluang, dan ancaman utama dalam organisasi, Analisa Value Chain, Metode Critical Success Factors (CSFs) Berdasarkan IT Balanced Scorecard, dan Mc Farlan's Strategic Grid. Hasil dari penelitian ini berupa perencanaan strategis sistem informasi dan teknologi informasi yang diharapkan dapat memberikan usulan atau masukan bagi tercapainya pemerintahan yang berbasis teknologi (E-Government) pada DISPERINNAKER Kota Salatiga.

Penelitian (Sampurna et al., 2015) menggunakan metode ward and peppard dengan tools, analisis SWOT, CSF, Value Chain, MCFarlan Strategic Grid sehingga hasilnya memberikan beberapa rekomendasi kepada Dishubkominfo dalam strategi sistem informasi, SI/TI yang terintegrasi manajemen, dan ditampilkan dalam portofolio sistem informasi MCFarlan yang 
dapat mendukung aktivitas bisnis dalam Dishubkominfo agar sesuai dengan tujuan pemerintah [5]. Penelitian (Baskoro et al., 2019) menggunakan metode Ward And Peppard yang terdiri dari analisis lingkungan bisnis internal, analisis lingkungan bisnis eksternal, analisis lingkungan teknologi informasi internal, analisis lingkungan teknologi informasi eksternal, CSF, dan analisis SWOT. Hasil dari penelitian tersebut berupa strategi teknologi informasi dokumen perencanaan untuk universitas IPB Program Diploma dengan output dalam bentuk aplikasi portofolio yang diusulkan, infrastruktur teknologi informasi desain dan strategi manajemen teknologi informasi [6].

\section{METODE PENELITIAN}

\subsection{Tinjauan Pustaka}

\subsubsection{Perencanaan Strategis Sistem Informasi}

Perencanaan strategis Sistem Informasi merupakan proses identifikasi portofolio aplikasi sistem informasi berbasis komputer yang akan mendukung organisasi/perusahaan dalam pelaksanaan rencana bisnis dan merealisasikan tujuan bisnisnya[1]. Perencanaan strategis SI/TI mempelajari pengaruh SI/TI terhadap kinerja bisnis dan kontribusi bagi organisasi dalam memilih langkah-langkah strategis. Selain itu, perencanaan strategis SI/TI juga menjelaskan berbagai tools, teknik, dan kerangka kerja bagi manajemen untuk menyelaraskan strategi SI/TI dengan strategi bisnis, bahkan mencari kesempatan baru melalui penerapan teknologi yang inovatif [7](Perencanaan Strategis Sistem Informasi / Teknologi Informasi Pada Perusahaan Manufaktur Menggunakan Metodologi, 2016).

\subsubsection{Metode Ward and Peppard}

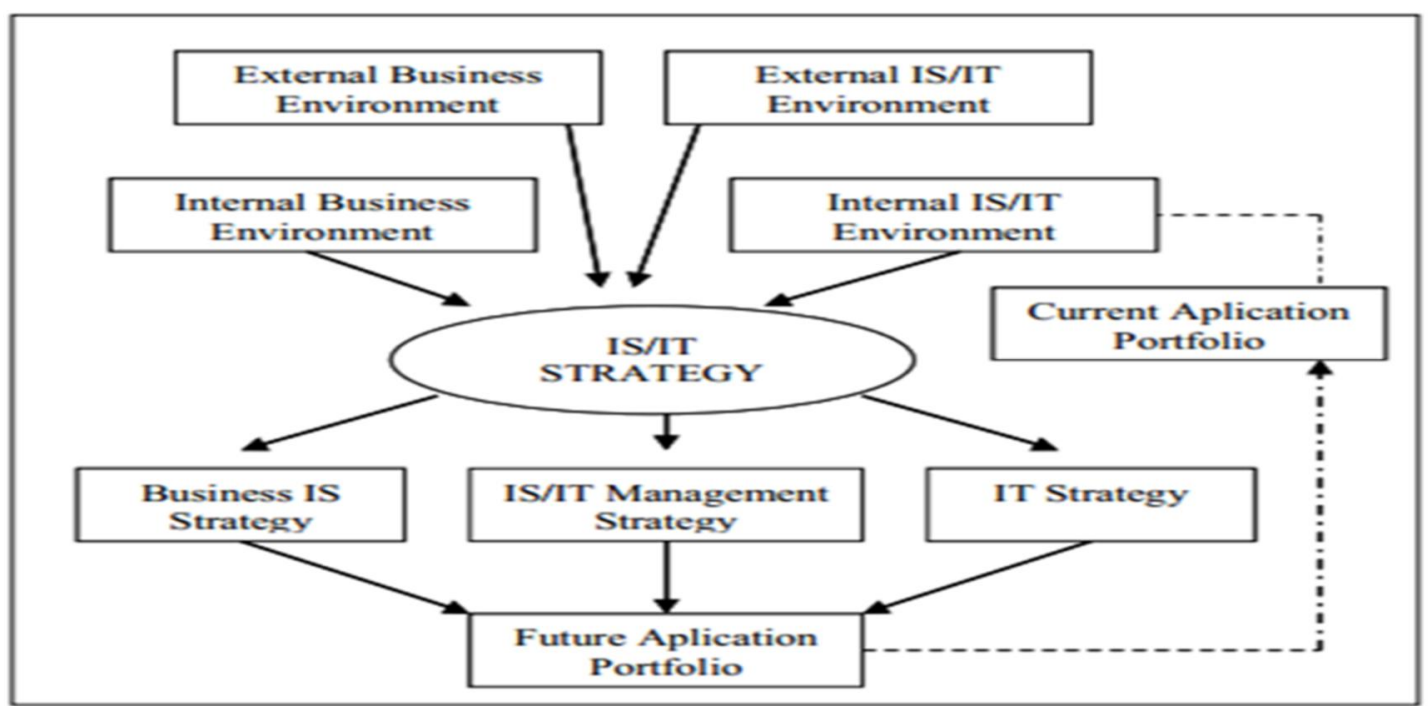

Gambar 1. Model Strategis SI/TI Ward and Peppard

Metode Ward and Peppard terdiri dari tahapan masukan dan tahapan keluaran. Tahapan masukan terdiri dari 4 macam analisis, antara lain, Analisis lingkungan bisnis internal yang mencakup aspek-aspek strategi bisnis saat ini yaitu sasaran, sumber daya, proses, serta nilainilai bisnis organisasi. Analisis lingkungan bisnis eksternal, yang mencakup aspek-aspek ekonomi, industri, dan iklim bersaing perusahaan. Analisis lingkungan SI/TI internal, yang 
mencakup kondisi SI/TI organisasi dari perspektif bisnis saat ini, bagaimana kematangannya, bagaimana kontribusi terhadap bisnis, keterampilan sumber daya manusianya, sumber dayanya dan infrastruktur teknologi, termasuk juga bagaimana portofolio dari SI/TI yang ada saat ini. Dan Analisis lingkungan SI/TI eksternal, yang mencakup teknologi dan peluang pemanfaatannya, serta penggunaan SI/TI oleh kompetitor, pelanggan dan pemasok. Sedangkan tahapan keluaran merupakan bagian yang dilakukan untuk menghasilkan suatu dokumen perencanaan strategis SI/TI yang isinya terdiri dari [1], Strategi sistem informasi bisnis, Strategi teknologi informasi, dan Strategi Manajemen SI/TI [8] (Ti et al., 2019).

\subsection{Tahap Penelitian}

Penelitian dilakukan pada Dinas Perindustrian dan Tenaga Kerja (DISPERINNAKER) Kota Salatiga yang berlokasi di JL. Ki Penjawi No.12 Salatiga. Penelitian dimulai pada tanggal 25 Februari 2021 sampai 03 Maret 2021 dengan melakukan wawancara kepada 4 narasumber yaitu kepada Ibu Siti Andjajanah selaku Sekretaris Dinas, Ibu Ben Ismi Daradasih selaku kepala bidang tenaga kerja dan bagian prakom yaitu Bapak Joko Pujianto dan Bapak Indra Wahyu Wibowo. Wawancara ini bertujuan untuk memahami keadaan proses kinerja pada organisasi tersebut secara lebih mendalam dan penerapan SI/TI yang sudah dilakukan organisasi tersebut. Metode penelitian yang akan digunakan pada DISPERINNAKER Kota Salatiga yaitu menggunakan metode kualitatif. Metode ini digunakan untuk mendeskripsikan data fakta serta teknik analisisnya [9] (Johannis et al., 2019). Penelitian ini mempunyai beberapa tahapan yang saling berkaitan, yaitu:

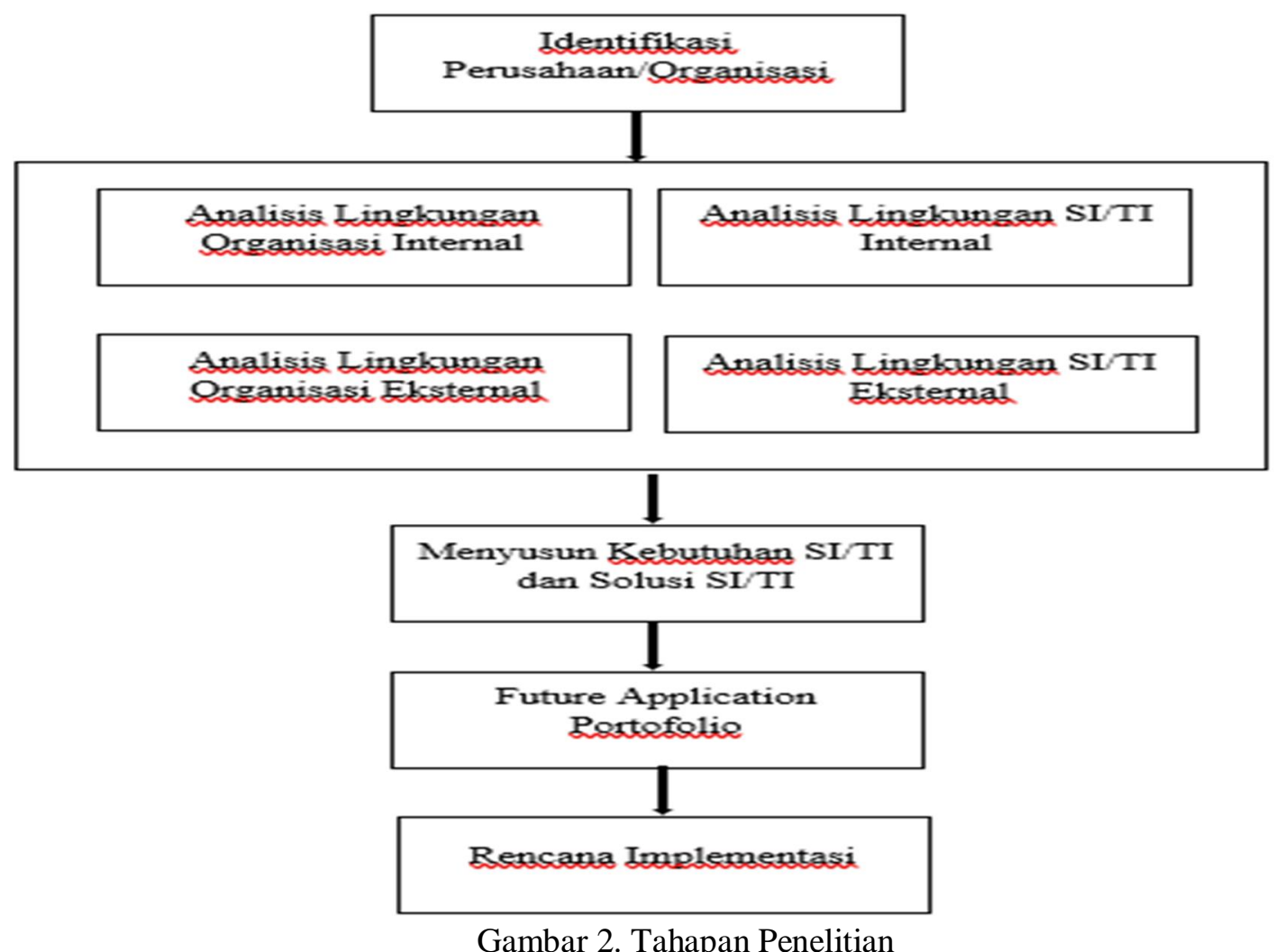


Tahapan 1 menggambarkan tentang bagaimana cara untuk mengumpulkan dan mengidentifikasi informasi yang ada pada DISPERINNAKER Kota Salatiga seperti (profil, visi misi dan tujuan organisasi dengan cara melakukan observasi dan wawancara. Tahapan 1 ini juga tahapan untuk mengetahui kekuatan, kelemahan, ancaman, dan peluang pada organisasi tersebut. Tahapan 2 adalah untuk menganalisis dan menyusun bagaimana kebutuhan SI/TI pada DISPERINNAKER Kota Salatiga yang nantinya dapat memberikan rekomendasi tentang kebutuhan SI/TI dan solusi SI/TI pada organisasi dengan menggunakan Analisis CSFs Berdasarkan IT Balanced Scorecard. Tahapan 3, berdasarkan analisis sebelumnya maka dapat diperoleh perencanaan strategis sistem informasi untuk menganalisis kebutuhan SI/TI yang dibutuhkan oleh DISPERINNAKER Kota Salatiga untuk masa yang akan datang dengan menggunakan analisis McFarlan Strategic Grid. Selanjutnya tahapan 4, berdasarkan hasil portofolio aplikasi dengan menggunakan analisis McFarlan Strategic Grid maka dapat dihasilkan perencanaan strategis sistem informasi untuk rencana implementasi yang akan dilakukan dalam 4 tahun yang akan datang.

\section{HASIL DAN PEMBAHASAN}

\subsection{Analisis SWOT}

Tahap Awal Analisis dilakukan dengan menggunakan tools Analisis Strength, Weaknesses, Opportunities, Threats (SWOT), yaitu identifikasi lingkungan secara sistematis untuk merumuskan strategi perusahaan[10]. Analisis SWOT digunakan untuk mengidentifikasi faktor-faktor Internal dan Eksternal. Analisis. Faktor internal digunakan untuk menentukan dan mengevaluasi kekuatan dan kelemahan organisasi, sedangkan analisis faktor eksternal digunakan untuk menentukan dan mengevaluasi peluang dan ancaman dari lingkungan di sekitar organisasi. Faktor strategis lingkungan internal dan eksternal diidentifikasi dengan membuat Matriks Evaluasi Faktor Internal dan Faktor Eksternal (IFE-EFE) [11] (Astuti \& Ratnawati, 2020).

Tabel 1. IFE ( Evaluasi Faktor Internal)

\begin{tabular}{|c|c|c|c|}
\hline Faktor Internal (Strength) & $\begin{array}{l}\text { Bobot } \\
\text { (Weight) }\end{array}$ & Rating & $\begin{array}{l}\text { Nilai Terbobot } \\
\text { (Weighted Score) }\end{array}$ \\
\hline $\begin{array}{l}\text { 1. Para Staff telah memahami visi misi dan } \\
\text { tugas-tugas jabatannya. }\end{array}$ & 0,10 & 3 & 0,30 \\
\hline $\begin{array}{l}\text { 2. Penyusunan materi perencanaan Renja, } \\
\text { DPA, RKPD, dan RKA SKPD telah } \\
\text { dilakukan sesuai dengan waktu yang sudah } \\
\text { ditetapkan. }\end{array}$ & 0,09 & 4 & 0,36 \\
\hline $\begin{array}{l}\text { 3. Melakukan kegiatan monitoring dan evaluasi } \\
\text { terhadap kegiatan yang sudah berjalan. }\end{array}$ & 0,02 & 3 & 0,06 \\
\hline $\begin{array}{l}\text { 4. Memiliki komitmen untuk mewujudkan } \\
\text { pemerintahan E-Government dan } \\
\text { memberikan informasi layanan publik yang } \\
\text { akurat dan berkualitas. }\end{array}$ & 0,05 & 4 & 0,20 \\
\hline $\begin{array}{l}\text { 5. Memiliki kerja sama dengan jasa } \\
\text { pemeliharaan dalam pengembangan dan } \\
\text { pengelolaan aplikasi DISPERINNAKER. }\end{array}$ & 0,05 & 3 & 0,15 \\
\hline 6. Sudah terdapat aplikasi yang dikembangkan & 0,15 & 4 & 0,60 \\
\hline
\end{tabular}


oleh DISPERINNAKER untuk melakukan pembuatan AK I-AK V (E-Makaryo), Sistem untuk Pengesahan Peraturan Perusahaan dan Pendaftaran Perjanjian Kerja Bersama (PPPKB), sistem untuk mempromosikan hasil dan penjualan produk IKM (SIMASTRI), Sistem untuk perizinan bidang industri (SIINAS) dan Web DISPERINNAKER.

7. Melakukan kegiatan koordinasi dan evaluasi antar bidang.

8. Terdapat ruang backup data untuk setiap aplikasi yang digunakan.

9. Adanya pengembangan melalui pelatihan dan bimtek terhadap para staf nya.

\begin{tabular}{l|l|l}
\hline & & \\
& & \\
& & \\
& & \\
\hline 0,02 & 3 & 0,06 \\
\hline 0,03 & 3 & 0,09 \\
\hline 0,05 & 3 & 0,15 \\
\hline
\end{tabular}

\section{Faktor Internal (Weaknesses)}

\begin{tabular}{l|l|l|l|}
\hline 1) Kurangnya SDM yang berkualitas. & 0,10 & 2 & 0,20
\end{tabular}

2) Belum adanya sistem untuk pengarsipan, surat menyurat, disposisi, aset-aset, dan perpustakaan.

3) Masih belum berjalan dengan maksimal kegiatan koordinasi antar bidang.

4) Jaringan internet yang belum stabil.

5) Pelayanan masih banyak yang belum terkomputerisasi.

6) Dilihat dari sisi anggaran dan administrasi masih mengalami kendala dalam ketidak sesuaian dengan penyusunan perencanaan.

7) Sarana dan prasarana yang belum memadai. Total

\begin{tabular}{|c|c|c}
\hline 0,10 & 2 & 0,20 \\
\hline 0,15 & 2 & 0,30 \\
0,02 & 1 & 0,02 \\
\hline 0,04 & 2 & 0,08 \\
0,05 & 2 & 0,10 \\
\hline 0,03 & 2 & 0,06 \\
\hline 0,05 & 2 & 0,10 \\
\hline $\mathbf{1 , 0 0}$ & & $\mathbf{2 , 8 3}$ \\
\hline
\end{tabular}

Dari hasil tabel matriks internal pada tabel 1 diatas dapat dilihat bahwa score faktor internal adalah $\mathbf{2 , 8 3}$.

Tabel 2. EFE (Evaluasi Faktor Eksternal)

\begin{tabular}{ll|c|c|c}
\hline & Faktor Eksternal (Opportunities) & $\begin{array}{c}\text { Bobot } \\
\text { (Weight) }\end{array}$ & Rating & $\begin{array}{c}\text { Nilai Terbobot } \\
\text { (Weighted Score) }\end{array}$ \\
\hline 1) & $\begin{array}{l}\text { Meningkatkan kualitas SDM yang sudah } \\
\text { ada. }\end{array}$ & 0,07 & 4 & 0,28 \\
\hline 2) & $\begin{array}{l}\text { Mengintegrasikan sistem yang sudah ada } \\
\text { dengan pemerintahan pusat. }\end{array}$ & 0,08 & 4 & 0,32 \\
\hline 3) & $\begin{array}{l}\text { Melakukan kegiatan koordinasi dan } \\
\text { evaluasi dengan instansi pemerintah agar } \\
\text { kegiatan berjalan dengan lancar. }\end{array}$ & 0,06 & 3 & 0,18 \\
\hline
\end{tabular}


4) Bekerja sama dengan pihak luar (perusahaan, industri, masyarakat, dll).

5) Melakukan koordinasi perubahan peraturan dari pemerintah pusat dengan cepat.

6) Tersedianya data-data pendukung dalam melakukan usulan perencanaan sudah sangat baik.

7) Memberikan pelayanan yang prima kepada masyarakat.

8) Informasi yang sangat dibutuhkan oleh masyarakat.

9) Meningkatkan sarana dan prasarana yang sudah ada.

10) Tersedianya sistem administrasi untuk meminimalisir ketidak sesuaian.

11) Tercapainya pemerintahan yang bersih.

\begin{tabular}{l|l|l|l} 
& 0,07 & 4 & 0,28 \\
\hline $\mathrm{n}$ & 0,03 & 3 & 0,09 \\
\hline $\mathrm{m}$ & 0,04 & 4 & 0,16 \\
\hline $\mathrm{a}$ & 0,04 & 4 & 0,16 \\
\hline $\mathrm{g}$ & 0,05 & 4 & 0,20 \\
\hline $\mathrm{k}$ & 0,07 & 3 & 0,21 \\
\hline & 0,06 & 3 & 0,18 \\
\hline
\end{tabular}

\section{Faktor Eksternal (Threats)}

1) Peluang cracking pada sistem yang ada di DISPERINNAKER.

2) Server down atau rusak dalam proses kinerjanya.

3) Bencana alam yang mungkin terjadi seperti (Wabah penyakit, gempa bumi, banjir, kebakaran, dll).

4) Peraturan pemerintahan yang mengalami perubahan setiap tahunnya.

5) Informasi pelayanan publik yang tidak sesuai.

6) Kurangnya kepercayaan oleh masyarakat.

7) Sistem perencanaan berupa usulan Renja tidak sesuai dengan susunan RKA.

\begin{tabular}{l|l|l|l}
\hline & 0,05 & 2 & 0,10 \\
\hline & 0,05 & 1 & 0,05 \\
\hline $\mathbf{i n}$ & 0,04 & 2 & 0,08 \\
\hline 0,07 & 2 & 0,14 \\
\hline 0,04 & 2 & 0,08 \\
\hline 0,07 & 1 & 0,07 \\
\hline & 0,04 & 1 & 0,04 \\
\hline
\end{tabular}

Dari hasil tabel matriks eksternal pada tabel 2 diatas dapat dilihat bahwa score faktor eksternal adalah 2,90. 


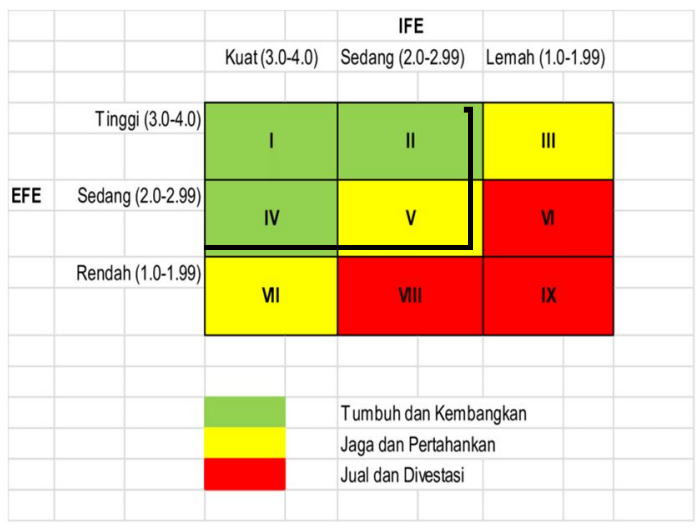

Gambar 3. Matriks IFE-EFE

Dari hasil penilaian Matriks Internal Eksternal untuk DISPERINNAKER diperoleh nilai IFE sebesar 2,83 dan score EFE sebesar 2,90 yang menunjukan posisi sedang pada kuadran 5 (Gambar 3), sehingga organisasi memiliki kemampuan untuk menangani faktor internal dan eksternal yang cukup baik.

\subsection{Analisa Value Chain}

Analisa Value Chain dilakukan untuk mengetahui seluruh proses kerja yang terjadi di DISPERINNAKER ke dalam dua kategori aktivitas yaitu aktivitas utama dan aktivitas pendukung [12] (Chandra \& Afni, 2017). Analisa (Akuntansi, n.d.) ini bertujuan untuk mengidentifikasi dan mengelompokkan aktivitas-aktivitas yang terjadi di perusahaan/organisasi ke dalam dua bagian besar yaitu aktivitas utama dan aktivitas pendukung [13]. Gambar 3 berikut menyajikan hasil Analisis value chain pada DISPERINNAKER Kota Salatiga.

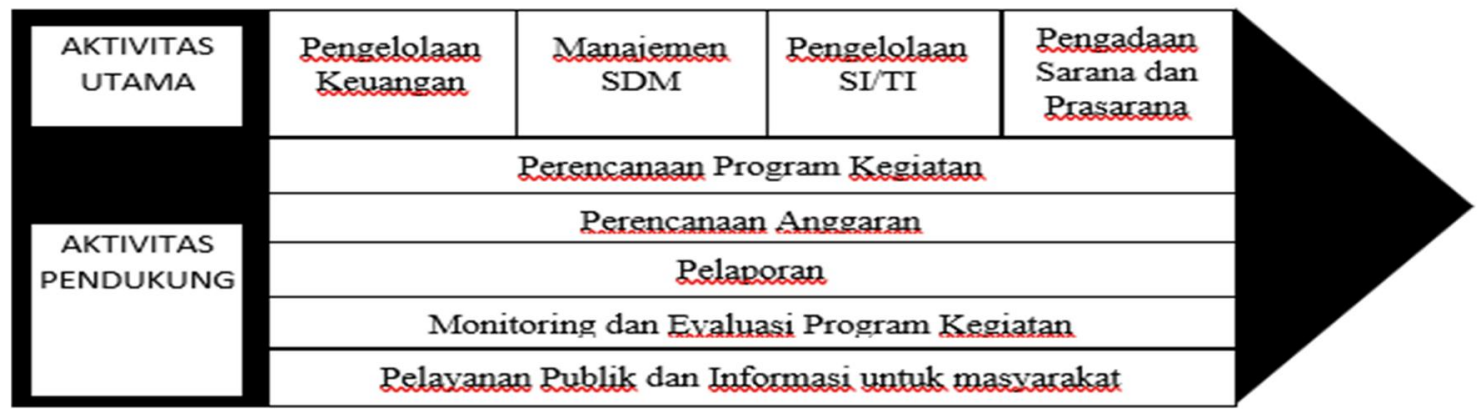

Gambar 4. Diagram Value Chain DISPERINNAKER Kota Salatiga

Identifikasi penerapan sistem informasi yang digunakan pada DISPERINNAKER secara internal dilakukan untuk mengetahui sejauh mana sistem yang dikembangkan saat ini oleh DISPERINNAKER Kota Salatiga. Berikut adalah daftar sistem informasi yang digunakan dan dikembangkan oleh DISPERINNAKER saat ini seperti pada tabel 3. 
Tabel 3. Penerapan SI pada DISPERINNAKER

\begin{tabular}{|c|c|c|c|}
\hline No & Nama Sistem & Pengguna & Jenis Aplikasi \\
\hline 1 & E-Makaryo & Admin & Web \\
2 & PPPKB & Bidang & Web \\
3 & SIMASTRI & Bidang & Web \\
4 & SIINAS & Bidang & Web \\
5 & Web DISPERINNAKER & Admin & Web \\
6 & SI Presensi & Umum & Face Recognition \\
\hline
\end{tabular}

Tabel 3 menjelaskan tentang penerapan sistem informasi yang saat ini sudah dikembangkan oleh DISPERINNAKER. Dengan adanya aplikasi E-Makaryo DISPERINNAKER dapat memberikan pelayanan pembuatan kartu tanda pencari kerja (AK1) kepada masyarakat. Aplikasi PPPKB bertujuan untuk mengetahui pengesahan peraturan perusahaan dan pendaftaran perjanjian kerja Bersama. Aplikasi SIMASTRI bertujuan untuk mempromosikan hasil dan penjualan IKM. Aplikasi SIINAS bertujuan memberikan perizinan bidang industri seperti, IUI, IUP, dan Izin Perluasan Kawasan. Web DISPERINNAKER menjadi website resmi yang dimiliki dan dikelola oleh DISPERINNAKER untuk menyediakan informasi kepada masyarakat. SI Presensi sebagai alat monitoring absensi pegawai yang bertujuan agar para pegawai menjadi disiplin dalam ketepatan waktu berangkat dan pulang kerja.

\subsection{Analisa Critical Success Factors (CSFs) Berdasarkan IT Balanced Scorecard}

Analisa Critical Success Factors (CSFs) dilakukan untuk mengetahui kebutuhan dari organisasi tersebut dan lingkungannya yang sangat berpengaruh pada keberhasilan atau kegagalan. Analisa Critical Success Factors (CSFs) dilakukan bertujuan untuk menginterpretasikan objektif secara lebih jelas untuk menentukan aktivitas yang harus dilakukan dan informasi apa yang dibutuhkan [14](Wandikbo \& Sitokdana, 2019). Analisa Critical Success Factors (CSFS) yang dilakukan pada DISPERINNAKER menggambarkan identifikasi faktor kesuksesan untuk melihat kebutuhan SI/TI yang dapat berpengaruh terhadap rencana implementasi SI/TI pada DISPERINNAKER Kota Salatiga di masa yang akan datang. Langkah selanjutnya adalah menentukan keberhasilan berdasarkan IT Balanced Scorecard, seperti yang terlihat pada tabel 4 .

Tabel 4. Menentukan CSFs Berdasarkan IT Balanced Scorecard

\begin{tabular}{|c|lr|r|c|}
\hline \multicolumn{9}{|c|}{ Perspektif Kontribusi Organisasi } \\
\hline No & \multicolumn{2}{|c|}{ Objektif (CSFs) } & \multicolumn{1}{c|}{ Key Decision } & $\begin{array}{c}\text { Solusi } \\
\text { Aplikasi }\end{array}$ \\
\hline 1 & $\begin{array}{l}\text { Terwujudnya sistem untuk } \\
\text { pengelolaan administrasi } \\
\text { berkualitas }\end{array}$ & $\begin{array}{l}\text { Membangun sistem untuk } \\
\text { fungsi administrasi yang } \\
\text { berkualitas }\end{array}$ & $\begin{array}{c}\text { SI } \\
\text { Administrasi }\end{array}$ \\
\hline \multicolumn{5}{|c|}{ Perspektif Orientasi Pengguna } \\
\hline 2 & $\begin{array}{l}\text { Terwujudnya sistem untuk } \\
\text { menampung aspirasi masyarakat dan } \\
\text { pelayanan publik yang akurat dan } \\
\text { berkualitas }\end{array}$ & $\begin{array}{l}\text { Membangun layanan publik } \\
\text { yang efisien dan berkualitas }\end{array}$ & $\begin{array}{c}\text { SI Ruang } \\
\text { Publik }\end{array}$ \\
\hline \multicolumn{4}{|c|}{ Perspektif Keunggulan Operasional } \\
\hline
\end{tabular}




\begin{tabular}{|c|c|c|c|}
\hline 3 & $\begin{array}{l}\text { Terwujudnya sistem yang sudah saling } \\
\text { terintegrasi dalam mencapai tujuan } E \text { - } \\
\text { Government }\end{array}$ & $\begin{array}{l}\text { Membangun sistem yang } \\
\text { sudah saling terintegrasi di } \\
\text { ruang lingkup internal dan } \\
\text { eksternal }\end{array}$ & $\begin{array}{c}\text { SI } \\
\text { Terintegrasi }\end{array}$ \\
\hline 4 & $\begin{array}{l}\text { Terwujudnya sistem untuk melakukan } \\
\text { koordinasi antar bidang dengan efektif } \\
\text { dan efisien }\end{array}$ & 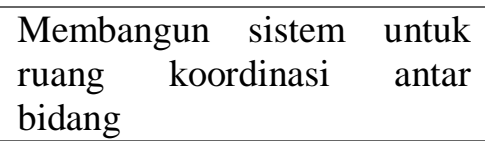 & $\begin{array}{c}\text { SI } \\
\text { Koordinasi }\end{array}$ \\
\hline 5 & $\begin{array}{l}\text { Membangun sistem untuk kerja sama } \\
\text { dengan pihak ketiga secara efektif dan } \\
\text { efisien dalam rencana program } \\
\text { kegiatan }\end{array}$ & $\begin{array}{l}\text { Melakukan ikatan kerja sama } \\
\text { dengan pihak ketiga untuk } \\
\text { membangun rencana } \\
\text { program kegiatan yang akan } \\
\text { dilakukan. }\end{array}$ & $\begin{array}{l}\text { SI Kerja } \\
\text { Sama }\end{array}$ \\
\hline 6 & 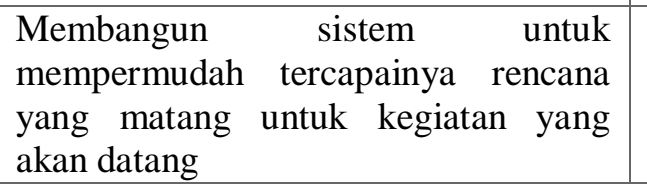 & $\begin{array}{l}\text { Rencana yang matang untuk } \\
\text { kegiatan jangka panjang dan } \\
\text { pendek }\end{array}$ & $\begin{array}{c}\text { SI } \\
\text { Perencanaan }\end{array}$ \\
\hline 7 & $\begin{array}{l}\text { Terwujudnya sistem yang dapat } \\
\text { melakukan pengelolaan SDM yang } \\
\text { berkualitas }\end{array}$ & $\begin{array}{lr}\text { Memberikan } & \text { fasilitas } \\
\text { terhadap SDM } & \text { yang } \\
\text { memiliki kompetensi } & \text { SI/TI } \\
\text { pada organisasi } & \end{array}$ & $\begin{array}{l}\text { SI } \\
\text { Pengelolaan } \\
\text { SDM }\end{array}$ \\
\hline 8 & $\begin{array}{l}\text { Tersedianya sistem untuk mengelola } \\
\text { asset-aset yang dimiliki organisasi }\end{array}$ & $\begin{array}{l}\text { Membangun sistem untuk } \\
\text { mengelola aset yang dimiliki } \\
\text { organisasi agar selalu } \\
\text { termonitoring }\end{array}$ & $\begin{array}{l}\text { SI } \\
\text { Manajemen } \\
\text { Aset }\end{array}$ \\
\hline 9 & $\begin{array}{l}\text { Membangun sistem untuk pengelolaan } \\
\text { buku }\end{array}$ & $\begin{array}{lr}\text { Pengelolaan buku } & \text { tentang } \\
\text { perindustrian } & \text { dan } \\
\text { ketenagakerjaan } & \end{array}$ & $\begin{array}{c}\text { SI } \\
\text { Perpustakaan }\end{array}$ \\
\hline 10 & $\begin{array}{l}\text { Meningkatkan sistem untuk } \\
\text { pengelolaan data sebagai pengarsipan } \\
\text { yang memadai }\end{array}$ & $\begin{array}{l}\text { Adanya pengelolaan data } \\
\text { pengarsipan yang memadai }\end{array}$ & $\begin{array}{l}\text { SI } \\
\text { Pengarsipan } \\
\text { Data }\end{array}$ \\
\hline 11 & $\begin{array}{l}\text { Membangun sistem informasi surat } \\
\text { untuk mempermudah kegiatan surat } \\
\text { menyurat dan disposisi menjadi lebih } \\
\text { efektif dan efisien }\end{array}$ & $\begin{array}{l}\text { E-Surat untuk mempermudah } \\
\text { kegiatan surat menyurat dan } \\
\text { penugasan yang terintegrasi }\end{array}$ & SIM Surat \\
\hline \multicolumn{4}{|c|}{$\begin{array}{l}\text { Perspektif Orientasi Masa Depan } \\
\end{array}$} \\
\hline 12 & 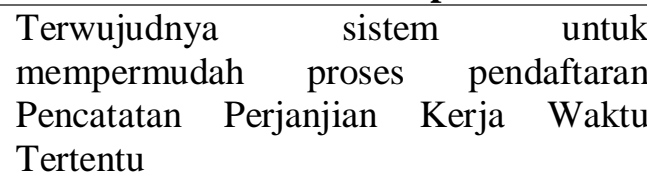 & \begin{tabular}{l|l}
$\mathrm{k}$ & Membangun sistem untuk \\
$\mathrm{n}$ & mempermudah proses \\
$\mathrm{u}$ & pendaftaran PKWT secara
\end{tabular} & $\begin{array}{l}\text { SI } \\
\text { Pendaftaran } \\
\text { PKWT }\end{array}$ \\
\hline 13 & $\begin{array}{l}\text { Terwujudnya sistem yang dapat } \\
\text { melakukan penyelesaian perselisihan } \\
\text { yang ada di hubungan industrial }\end{array}$ & $\begin{array}{l}\text { Membangun } \\
\text { dapat } \\
\text { penyelesaian } \text { melakukang } \\
\text { industrial secara online }\end{array}$ & SI PPHI \\
\hline
\end{tabular}

Keempat perspektif IT Balanced Scorecard menggambarkan bahwa berdasarkan Perspektif Kontribusi Organisasi yaitu fokus pada sistem administrasi dan rencana biaya sehingga organisasi dapat menghadapi tekanan kompetitif dari luar. Selanjutnya berdasarkan Perspektif Orientasi Pengguna yaitu membangun dan mengembangkan sistem untuk 
memecahkan masalah, keluhan pelanggan, komunikasi, kepuasan pelanggan, sehingga dapat mempertahankan pelanggan yang sudah ada dan meningkatkan jumlah pelanggan baru. Berdasarkan Perspektif Keunggulan Operasional fokus kepada sistem yang menunjang organisasi seperti membangun sistem untuk mencapai E-Government. Selanjutnya berdasarkan Perspektif Orientasi Masa Depan yaitu membangun sistem yang dibutuhkan untuk memberikan kemudahan dalam menyediakan pelayanan kepada masyarakat dan memberikan kelancaran dalam melakukan proses kinerjanya.

\subsection{McFarlan Strategic Grid}

Portofolio McFarlan Strategic Grid digunakan untuk memetakan aplikasi sistem informasi berdasarkan kontribusinya terhadap organisasi[15](Wiyono \& Wijaya, 2020) di masa yang akan datang. Pada tabel 5 berikut menggambarkan tentang pemetaan aplikasi sistem informasi yang dapat memberikan kemudahan pada organisasi dengan menyesuaikan kebutuhan organisasi saat ini dan dimasa mendatang.

Tabel 5. Portofolio SI Mendatang Berdasarkan McFarlan Strategic Grid

\begin{tabular}{|c|c|}
\hline Strategic & High Potential \\
\hline SI Terintegrasi & SI Pengelolaan SDM \\
\hline SI Ruang Publik & SIM Surat \\
\hline SI Pengarsipan Data & SI Administrasi \\
\hline SI Kerja Sama & SI Perencanaan \\
\hline SI Koordinasi & $\begin{array}{c}\text { SI Pendaftaran } \\
\text { PKWT }\end{array}$ \\
\hline Key Operational & Support \\
\hline E-Makaryo & SI Manajemen Aset \\
\hline PPPKB & SI Presensi \\
\hline SIMASTRI & SI Perpustakaan \\
\hline SIINAS & SI PPHI \\
\hline
\end{tabular}

Kuadran Key Operational merupakan kuadran dengan aplikasi yang saat ini menjadi keberhasilan DISPERINNAKER, dengan begitu kuadran Key Operational ditentukan dengan melihat aktivitas yang dilakukan di DISPERINNAKER. Kuadran Support, yaitu aplikasi yang mempunyai nilai berharga namun tidak menjadikan sebagai kesuksesan dalam organisasi tersebut. Kuadran Strategic merupakan aplikasi yang sangat rentan dan sangat berpengaruh terhadap proses kinerja dalam meningkatkan organisasi di masa mendatang. Selanjutnya Kuadran High Potential dimana aplikasi bukanlah hanya dianggap penting saja tetapi untuk menunjang setiap aktivitasnya dalam berlangsungnya proses kinerja organisasi di masa yang akan datang.

\subsection{Rencana Implementasi}

Berdasarkan hasil dari usulan portofolio aplikasi pada DISPERINNAKER yang sesuai dengan kebutuhan solusi SI yang akan datang. Tahap selanjutnya yaitu Menyusun rencana implementasi atau pengembangan dari hasil tersebut. Hal ini dilakukan dengan cara memetakan rencana dalam kurun empat tahun yang akan datang berdasarkan kebutuhan SI. Berikut dapat dilihat pada tabel 6 . 
Tabel 6. Rencana Implementasi SI pada DISPERINNAKER

\begin{tabular}{|l|c|c|c|c|}
\hline \multicolumn{1}{|c|}{ Aplikasi } & $\mathbf{2 0 2 1}$ & $\mathbf{2 0 2 2}$ & $\mathbf{2 0 2 3}$ & $\mathbf{2 0 2 4}$ \\
\hline - SI Pengelolaan SDM & High & & \\
- SIM Surat & Potential & & \\
- SI Administrasi & & & \\
- SI Perencanaan & & & \\
- SI Pendaftaran PKWT & & Strategic & & \\
\hline - SI Koordinasi & & & \\
- SI Kerja Sama & & & \\
- SI Pengarsipan Data & & & & \\
- SI Ruang Publik & & & Key & \\
- SI Terintegrasi & & & \\
\hline - E-Makaryo & & & Operational & \\
- PPPKB & & & \\
- SIMASTRI & & & \\
- SIINAS & & & \\
\hline - SI Manajemen Aset & & & \\
- SI Presensi & & & \\
- SI Perpustakaan & & & \\
- SI PPHI & & & \\
\hline
\end{tabular}

Tabel 6 ini menjelaskan tentang rencana implementasi pada DISPERINNAKER Kota Salatiga. Pada tahun 2021 rencana implementasi fokus kepada kuadran High Potential karena aplikasi tersebut dapat meningkatkan keberhasilan organisasi. Implementasi pada tahun 2022 fokus pada kuadran strategic, agar organisasi dapat lebih meningkatkan aplikasi yang rentan terhadap proses kinerjanya di masa yang akan datang. Tahun 2023 yaitu mengembangkan aplikasi yang sudah dikembangkan oleh DISPERINNAKER dengan kuadran Key Operational sehingga nantinya aplikasi tersebut dapat diupgrade agar lebih efektif dan efisien. Selanjutnya pada tahun 2024 rencana implementasi fokus kepada kuadran Support karena aplikasi yang berharga digunakan untuk membantu meningkatkan aktivitas kinerja menjadi lebih mudah.

\section{KESIMPULAN}

DISPERINNAKER memiliki kekurangan terhadap pengelolaan SDM, manajemen SI/TI, integrasi sistem dan masih belum menerapkan sistem informasi di setiap bagian organisasi sehingga perencanaan pengembangan belum terarah dengan baik. Oleh karena itu, dengan adanya perencanaan strategis menggunakan metode Ward and Peppard dapat diketahui kekuatan, kelemahan, peluang, serta ancaman (Analisis SWOT) dengan tambahan Matrik IFE dan $E F E$ yang digunakan untuk mengevaluasi faktor-faktor internal dan eksternal pada DISPERINNAKER. Selain itu juga dapat mengetahui aktivitas utama dan aktivitas pendukung yang dijelaskan dengan menggunakan tools value chain, Metode Critical Success Factors (CSFs) Berdasarkan IT Balanced Scorecard Solusi sistem informasi yang dipetakan dengan portofolio aplikasi McFarlan Grid menghasilkan 18 (delapan belas) usulan prioritas sistem informasi yaitu E-Makaryo, PPPKB, SIMASTRI, SIINAS, SI Manajemen Aset, SI Presensi, SI Perpustakaan, SI PPHI, SI Terintegrasi, SI Ruang Publik, SI Pengarsipan Data, SI Kerja Sama, SI Koordinasi, SI Pengelolaan SDM, SIM Surat, SI Administrasi, SI Perencanaan, SI Pendaftaran PKWT. Usulan sistem informasi tersebut dapat diterapkan dalam kurun waktu 4 
tahun (2021-2024), sehingga dapat meningkatkan kualitas organisasi dalam penerapan SI/TI dalam mendukung pencapaian visi dan misi DISPERINNAKER Kota Salatiga.

\section{SARAN}

Saran yang bisa disampaikan untuk penelitian kedepannya yaitu penelitian selanjutnya melakukan Analisis dan mengidentifikasi perangkat keras yang digunakan dalam mendukung proses kinerjanya. Dengan menguji kecepatan dan kapasitas perangkat keras untuk kelancaran dalam memenuhi tugas organisasi.

\section{DAFTAR PUSTAKA}

[1] Thomas, K. 2014, Perencanaan Strategis Sistem Informasi Dalam Meningkatkan Keunggulan Kompetitif Menggunakan Metode Ward \& Peppard (Studi Kasus SMK Diponegoro Salatiga), Program Studi Sistem Informasi FTI-UKSW, http://repository.uksw.edu/handle/123456789/8776

[2] Sudiarsa, K. 2011, Analisis Realisasi Program Badan Perencanaan Pembangunan Daerah (Bappeda) Kabupaten Buleleng.

[3] Kemkominfo. 2003, Kebijakan dan Strategi Nasional Pengembangan E-Government, Igarss 2014, 2004 (1), 1-5.

[4] Clement, H., \& Salois-Swallow, D. 1995, Strategic Planning For An Information System. In Medinfo. MEDINFO: Vol. 8 Pt 2. https://doi.org/10.1016/0024-6301(90)90122-k

[5] Sampurna, A. L., Darmawan, A., \& Nugroho, H. W. 2015, The Usage of Ward and Peppard Method in IS/IT Strategic Plan Compilation in Dishubkominfo East Lampung, International Conference On Information Technology and Business, August, 205-212. https://media.neliti.com/media/publications/171459-EN-the-usage-of-ward-and-peppardmethod-in.pdf

[6] Baskoro, R. G., Nurhadryani, Y., \& Purwanto, B. P. 2019, Jurnal Penelitian Pos dan Informatika Information Technology Strategic Plan Using Ward and Peppard Method (A Case Study of The Diploma Program of IPB (University) Perencanaan Strategis Teknologi Informasi Menggunakan Metode Ward and Peppard Studi Kasus. 9 (1), 13-26, https://doi.org/10.17933/jppi.2019.090

[7] _ 2016, Perencanaan Strategis Sistem Informasi/Teknologi Informasi pada Perusahaan Manufaktur Menggunakan Metodologi, 682010094.

[8] Ti, S. I., Firmansyah, Y., \& Purwaningtias, D. 2019, Tinjauan Metodologi Ward dan Peppard Dalam Menentukan Perencanaan Strategis SI/TI pada Perusahan, December 2017, https://doi.org/10.29406/cbn.v1i02.725s 
[9] Johannis, M. F., Tanaamah, A. R., \& Chernovita, H. P. 2019, Perencanaan Strategis Sistem Informasi Menggunakan Metode Ward and Peppard (Studi Kasus: CV.Grafika
Prima
Mitra
Ambon).
Sebatik,
23
(2),
611-618. https://doi.org/10.46984/sebatik.v23i2.818

[10] R. Freddy, "Analisis SWOT: Teknik Membedah Kasus Bisnis Cara Perhitungan Bobot, Rating, dan OCAI," PT. Gramedia, 2013. [Online]. Available: https://openlibrary.telkomuniversity.a.id/, [Accessed Jan. 27, 2019].

[11] Astuti, A. M. I., \& Ratnawati, S. 2020, Analisis SWOT Dalam Menentukan Strategi Pemasaran (Studi Kasus di Kantor Pos Kota Magelang 56100), Jurnal Ilmu Manajemen, 17(1), 58-70.

[12] Chandra, S. D., \& Afni, I. N. 2017, Perencanaan Strategis Sistem Informasi dan Teknologi Informasi Pendidik dan Ketenaga Pendidikan Oleh. I-Robot, 1(1), 1-25.

[13] Akuntansi, J. K. (n.d.), Perancangan Rencana Strategis Sistem Informasi dan Teknologi Informasi (SI/TI): Studi Kasus STMIK XYZ Maryani; Suparto Darudiato, 77-85.

[14] Wandikbo, D., \& Sitokdana, M. N. N. 2019, Perencanaaan Strategis Sistem Informasi di Yayasan Binterbusih Semarang Menggunakan Ward and Peppard, 1, 61-69.

[15] Wiyono, A., \& Wijaya, A. F. 2020. Perencanaan Strategis Sistem, Nformasi di PT Telekomunikasi Indonesia, Tbk Witel Semarang Menggunakan Ward and Peppard, Jurnal Bina Komputer, 2(1), 23-32. https://doi.org/10.33557/binakomputer.v2i1.797 